\title{
Acute airway failure secondary to thyroid metastasis from renal
} carcinoma

\author{
Mario Testini*1, Germana Lissidini ${ }^{1}$, Angela Gurrado1 ${ }^{1}$ Gaetano Lastilla², \\ Amato Stabile Ianora ${ }^{3}$ and Raffaele Fiorella ${ }^{4}$
}

Address: ${ }^{1}$ Department of Applications in Surgery of Innovative Technologies; University Medical School of Bari, Italy, ${ }^{2}$ Department of Pathology; University Medical School of Bari, Italy, ${ }^{3}$ Department of Radiology; University Medical School of Bari, Italy and ${ }^{4}$ Department of Otorhinolaryngology; University Medical School of Bari, Italy

Email: Mario Testini* - mario.testini@tin.it; Germana Lissidini - germanalissidini@hotmail.com; Angela Gurrado - angelagurrado@libero.it; Gaetano Lastilla - mario.testini@tin.it; Amato Stabile Ianora - mario.testini@tin.it; Raffaele Fiorella - mario.testini@tin.it

* Corresponding author

Published: 5 February 2008

World Journal of Surgical Oncology 2008, 6:14 doi:10.1 186/1477-7819-6-14

This article is available from: http://www.wjso.com/content/6/1/14

(c) 2008 Testini et al; licensee BioMed Central Ltd.

This is an Open Access article distributed under the terms of the Creative Commons Attribution License (http://creativecommons.org/licenses/by/2.0), which permits unrestricted use, distribution, and reproduction in any medium, provided the original work is properly cited.

\begin{abstract}
Background: Secondary involvement of the thyroid gland by malignant metastases is uncommon. Acute respiratory crisis due to infiltration of the upper airways is a recognised complication of anaplastic thyroid carcinoma or thyroid lymphoma. Renal cell carcinoma is a tumour that metastasizes diffusely and in an unpredictable manner.
\end{abstract}

Case presentation: We report a case of a 73-year-old man with a painful neck mass, dyspnoea, stridor and dysphonia that was evaluated in emergency. A right radical nephrectomy for renal cell carcinoma was performed 8 years previously. An emergency endotracheal intubation was followed by total thyroidectomy. Histological examination confirmed the diagnosis of thyroid metastasis from renal cell carcinoma.

Conclusion: A literature review regarding emergency treatment for acute respiratory compromise resulting from secondary thyroid tumours was undertaken. Only two cases of metastatic colon cancer and one case of metastatic meningioma requiring emergency thyroidectomy for acute respiratory failure are reported in the literature. This appears to be the first case of emergency surgery performed for acute respiratory compromise due to thyroid metastasis from renal cell carcinoma.

\section{Background}

Acute respiratory obstruction is an uncommon complication of thyroid disease. Most commonly it is due to hemorrhage within a multinodular goiter, bulky mediastinal goiter, anaplastic carcinoma or lymphoma [1-7]. Symptomatic metastases to the thyroid gland are rare, and patients usually complain of a palpable nodule, hoarseness, dysphagia and pain $[8,9]$. More rarely, it may present with breathing difficulty. In the present report, we describe a patient with thyroid metastases from renal cell carcinoma who presented clinically with acute respiratory failure. Two other similar cases reported in the medical literature are reviewed.

\section{Case presentation}

A 73-year-old man was admitted in emergency to the general surgery department with a neck mass, sudden dyspnoea, stridor, dysphonia, and progressively worsening 
dysphagia. His medical history included a multinodular goiter ans right radical nephrectomy performed 8 years prior due to renal cell carcinoma. At annual follow-up, a CT of the thorax and abdomen was performed and the thyroid mass was also evaluated by ultrasonography and thyroid function tests. Five months earlier, the patient had undergone fine-needle aspiration consistent with multinodular goiter. Three days before admission the patient underwent a total-body CT scan that revealed a thyroid mass with substernal extension involving and obstructing the upper airways, right vocal cord and jugular vein and showed carotid artery compression and displacement, in addition to diffuse lymphadenopathy (Figure 1).

Physical examination revealed a large, painful, diffuse, and predominantly right-sided thyroid tumour. Thyroid function tests were normal. A flexible laryngoscopy revealed right vocal cord palsy and left vocal cord paresis, with a nearly total reduction of the laryngeal lumen. Emergency endotracheal intubation was performed, followed by total thyroidectomy using loupe magnification [10] with lymph node dissection. The surgery was completed by a tracheotomy, given the evident tracheomalacia. The thyroid gland was found to have been fully replaced by a soft yellow mass weighing $40 \mathrm{~g}$ and $8.5 \times 5.5$ $\times 4.5 \mathrm{~cm}$ large, with indistinct borders infiltrating perithyroid muscles and involving three lymph nodes. Histological examination revealed a carcinoma composed mainly of clear cells with scanty oxyphil cells. Neoplastic cells showed large pleomorphic nuclei and frequent mitoses. Lymphatic and vascular invasions were common findings. Immunohistochemistry revealed strong and dif-
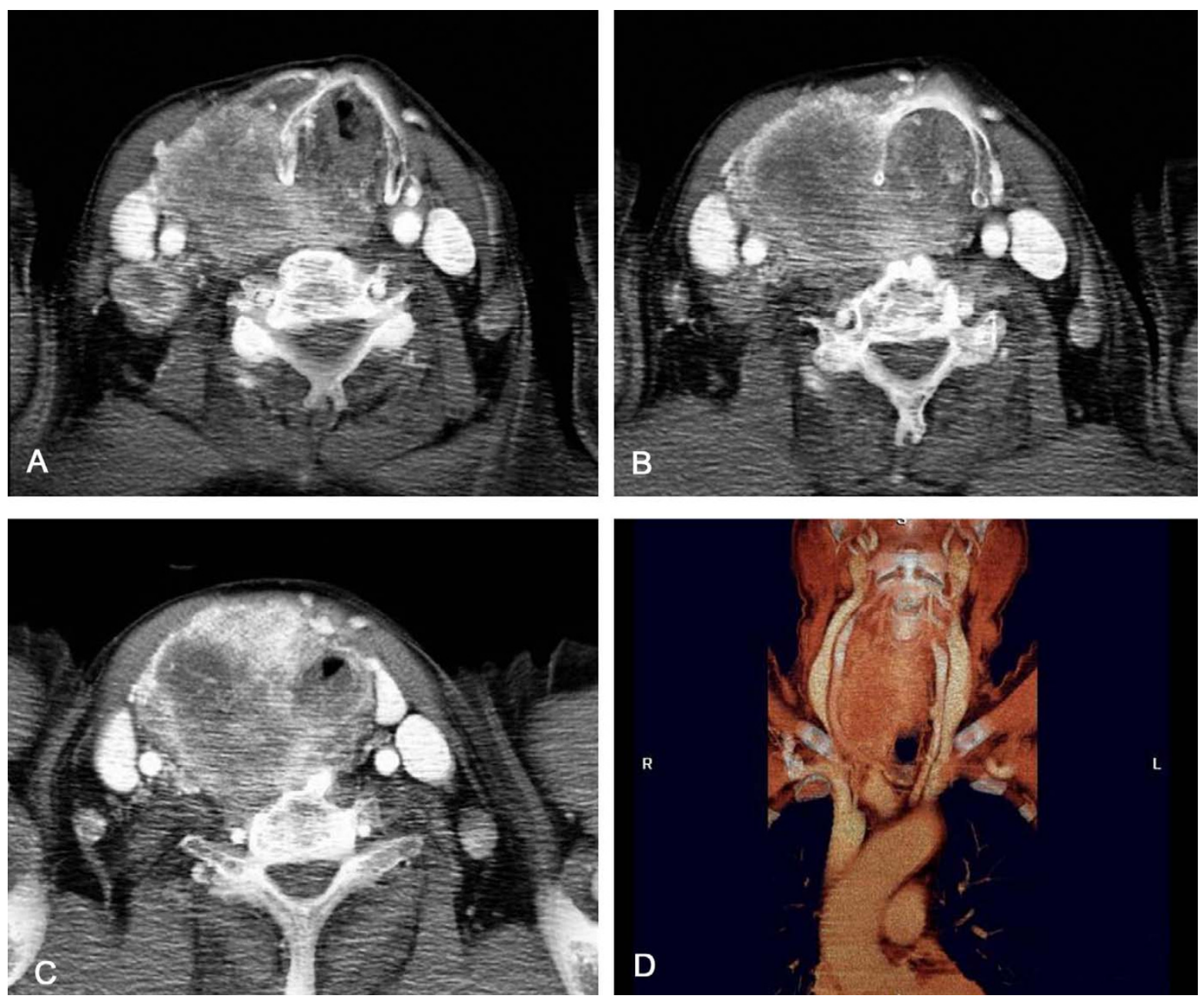

\section{Figure I}

Thyroid metastases due to renal cell carcinoma. Contrast-enhanced computed tomography scan: (A, B, C) axial images and (D) volume-rendered reconstructed image; the right lobe of the thyroid gland shows a non-homogeneous and irregular mass with tracheal involvement. The mass extends into the fatty plane in proximity to the right carotid artery and is also associated with metastatic lymph nodes. 

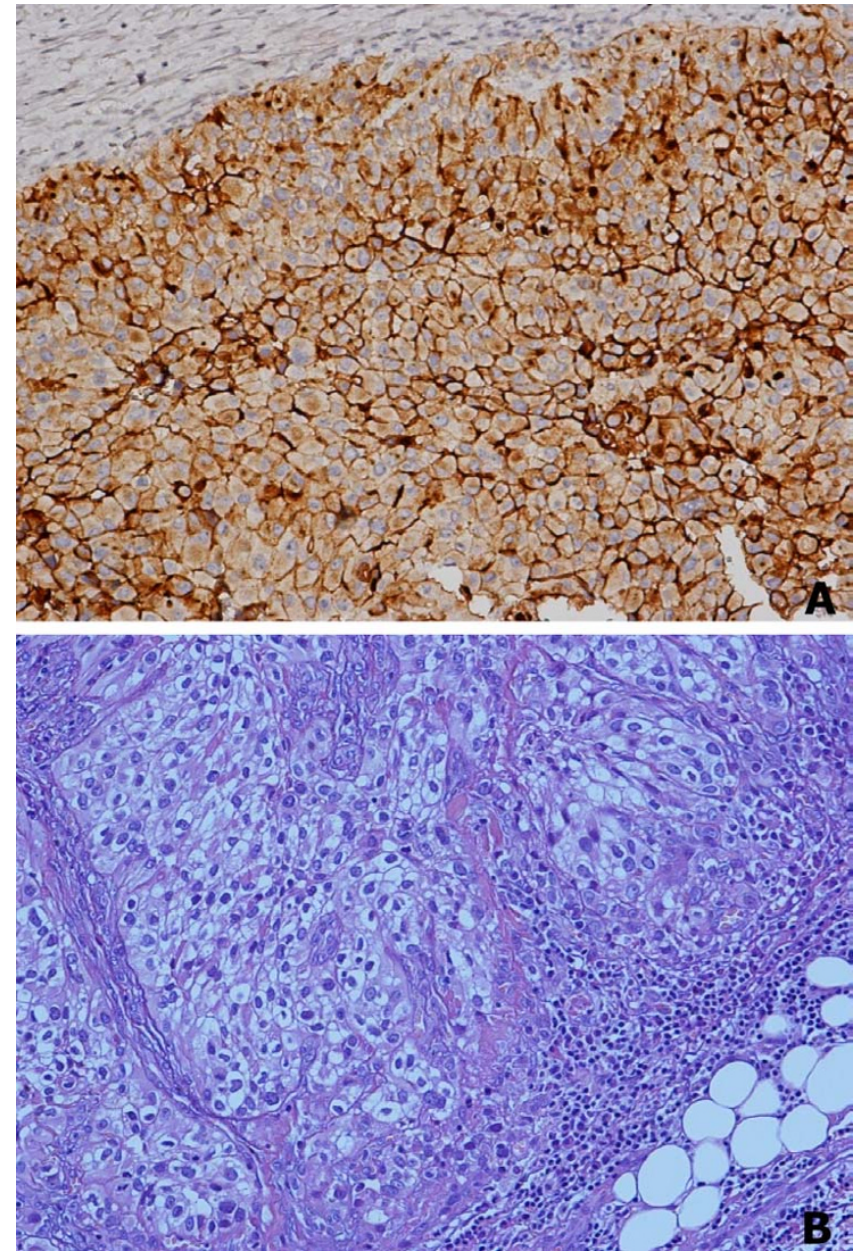

Figure 2

Histological findings. A) Neoplastic cells strongly expressed CDIO antigen (Immunoperoxidase, $\times 200$ ). B) Histology revealed a diffuse growth of neoplastic cells with an evident clear cytoplasm (hematoxylin and eosin, $\times 200$ ).

fuse expression of CD10 antigen (Figure 2A-B) was positive for Vimentin and negative for thyroid transcription factor-1 staining. Histology and immunohistochemistry were characteristic of metastatic clear renal cell carcinoma.

The patient had an uneventful postoperative course and was discharged after 10 days. Despite palliative chemotherapy, the disease progressed and the patient died 7 months later.

\section{Discussion}

The diagnosis is often incidental, resulting from histological examination of single nodule or multinodular goitre. Although our case produced unsuccesful results, fine-needle aspiration cytology plays an important role in diagnosing thyroid metastasis and is recommended by some authors. Secondary malignancies of the gland are believed to comprise less than $1 \%$ of thyroid cancers [8]. The overall incidence of metastases to the thyroid varies from $1.2 \%$ in unselected autopsy series to $24 \%$ in autopsy of patients with widespread malignant neoplasms [11].

Autopsy series reveal that thyroid metastases are most commonly due to breast, lung, melanoma, renal, and gastrointestinal carcinomas $[8,11]$. However, when only clinically relevant metastases are considered, the incidence of renal cell carcinoma increases to 50\% [8].

The thyroid gland is highly vascularized and its rich vascular supply inibits the embolization of tumoural cells. The reduced arterial supply and tissue iodine concentration of adenomatous gland, as in this case report, have been previously recognised as risk factors for the growth of metastatic malignant cells $[8,9,11]$. Renal cell carcinoma can metastasize to the thyroid bypassing the lungs via the valveless paravertebral venous plexus of Batson [12], exceptionally representing the first manifestation of widespread tumour dissemination. Recurrence may develop several years after the original diagnosis of the primary lesion, without specific signs or symptoms. Moreover, no sensitive tests assist in the preoperative diagnosis, as was demonstrated in this report by a standard fine-needle aspiration biopsy $[11,13,14]$ and absence of thyrotoxicosis that is contrary to previous reports [15].

Acute respiratory crisis caused by infiltration of the upper airways is a recognised complication in both the anaplastic thyroid carcinoma and in local squamous cell malignancies [16]. To investigate cases similar to ours, we conducted a Medline search from 1966 to 2007 using the key words "renal cell carcinoma with thyroid/acute airway failure/emergency surgery, and thyroid metastases with acute airway failure/emergency surgery/emergency treatment" in the title and abstract fields. Results showed that emergency surgery for acute respiratory failure due to secondary thyroid tumours was needed only in two cases of metastatic colon cancer [17] and in one case of metastatic meningioma [18]. The present report illustrates an additional case of acute airway obstruction resulting from thyroid metastatic disease. This case expands the spectrum of clinical manifestations described for thyroid metastases from renal cell carcinoma.

\section{Conclusion}

Increasing attention to concomitant thyroid disease is mandatory in patients who have undergone nephrectomy for renal cell carcinoma to improve follow-up accuracy and to avoid the rare but dramatic complication described herein. Studies focusing on prophylactic total thyroidectomy in the presence of a diagnosis of multinodular goiter 
during follow-up of patients with a history of renal cell carcinoma, should be encouraged.

\section{Competing interests}

The author(s) declare that they have no competing interests.

\section{Authors' contributions}

MT: the surgeon; approved the final version of the manuscript for publication. GL responsible for critical revision of scientific content AG drafted the manuscript. GL performed histopathological and immunohistochemical analyses and contributed to the pathology content. ASI performed the CT examination. RF contributed substantially to manuscript conception and design.

All authors read and approved the final version of the manuscript.

\section{Acknowledgements}

Written informed consent was obtained from relative of patient for publication of this case report.

\section{References}

I. Armstrong WB, Funk GF, Rice DH: Acute airway compromise secondary to traumatic thyroid hemorrhage. Arch Otolaryngol Head Neck Surg 1994, I 20:427-30.

2. Shaha AR, Burnett C, Alfonso A, Jaffe BM: Goiters and airway problems. Am J Surg 1989, I 58:378-380.

3. McHenry CR, Piotrowski Jj: Thyroidectomy in patients with marked thyroid enlargement: airway management, morbidity and outcome. Am Surg 1994, 60:586-591.

4. Myatt HM: Acute airway obstruction due to primary thyroid Iymphoma. Rev Laryngol Otol Rhinol (Bord) 1996, I I 7:237-239.

5. Kennedy KS, Wilson JF: Malignant thyroid lymphoma presenting as acute airway obstruction. Ear Nose Throat J 1992, 7 I(8):350-355.

6. Van Ruiswyk J, Cunningham C, Cerletty J: Obstructive manifestations of thyroid Iymphoma. Arch Intern Med 1989, | 49:1575-1577.

7. Poon D, Toh HC, Sim CS: Two case reports of metastases from colon carcinoma to the thyroid. Ann Acad Med Singapore 2004, 33:100-102.

8. Haugen BR, Nawaz S, Cohn A, Shroyer K, Bunn PA Jr, Liechty DR, Ridgway EC: Secondary malignancy of the thyroid gland: a case report and review of the literature. Thyroid 1994, 4:297-300.

9. Heffess CS, Wenig BM, Thompson LD: Metastatic renal cell carcinoma to the thyroid gland. A clinopathologic study of 36 cases. Cancer 2002, 95:1869-1878.

10. Testini M, Nacchiero M, Piccinni G, Portincasa P, Di Venere B, Lissidini G, Bonomo GM: Total thyroidectomy is improved by loupe magnification. Microsurgery 2004, 24:39-42.

II. Berge T, Lundberg S: Cancer in Malmo 1958-1969. An autopsy study. Acta Pathol Microbiol Scand Suppl 1977, 260: I-235.

12. Batson OV: The function of the vertebral veins and their role in the spread of metastases. Ann Surg 1940, I I 2: I 38- I 49.

13. Niiyama H, Yamaguchi K, Nagai F, Furukawa K, Torisu M, Tanaka M: Thyroid gland metastases from renal cell carcinoma masquerading as nodular goitre. Aust NZJ Surg 1994, 64:286-288.

14. Green LK, Ro JY, Mackay B, Ayala AG, Luna MA: Renal cell carcinoma metastatic to the thyroid. Cancer 1989, 63:1810-1815.

15. Miyakawa M, Sato K, Hasegawa M, Nagai A, Sawada T, Tsushima T, Takano K: Severe thyrotoxicosis induced by thyroid metastasis of lung adenocarcinoma: a case report and review of the literature. Thyroid 2001, I I:883-888.
16. Carter M, Path MRC, Path DR, Milroy CM, Path MRC: Thyroid carcinoma causing fatal laryngeal occlusion. J Laryngol Otol 1996, I | 0: I I 76- I I 78.

17. Witt RL: Colonic adenocarcinoma metastatic to thyroid Hurtle cell carcinoma presenting with airway obstruction. Del Med J 2003, 75:285-288.

18. Hasan R, Marshall MC Jr, Medhi M, Arshad A, Braun A, Panageas E: Meningioma metastatic to thyroid gland. Endocr Pract 2001, 7:370-374.
Publish with Biomed Central and every scientist can read your work free of charge

"BioMed Central will be the most significant development for disseminating the results of biomedical research in our lifetime. "

Sir Paul Nurse, Cancer Research UK

Your research papers will be:

- available free of charge to the entire biomedical community

- peer reviewed and published immediately upon acceptance

- cited in PubMed and archived on PubMed Central

- yours - you keep the copyright
BioMedcentral 